\title{
Unusual Complex Formation and Chemical Reaction of Haloacetate Anion on the Exterior Surface of Cucurbit[6]uril in the Gas Phase
}

\author{
Tae Su Choi, ${ }^{1}$ Jae Yoon Ko, ${ }^{1}$ Sung Woo Heo, ${ }^{1}$ Young Ho Ko, ${ }^{2}$ Kimoon Kim,,${ }^{1,2}$ \\ Hugh I. Kim ${ }^{1}$ \\ ${ }^{1}$ Department of Chemistry, Pohang University of Science and Technology, Pohang, Gyeongbuk, Korea \\ ${ }^{2}$ Center for Smart Supramolecules and Division of Advanced Materials Science, Pohang University \\ of Science and Technology, Pohang, Gyeongbuk, Korea
}

\begin{abstract}
Noncovalent interactions of cucurbit[6]uril (CB[6]) with haloacetate and halide anions are investigated in the gas phase using electrospray ionization ion mobility mass spectrometry. Strong noncovalent interactions of monoiodoacetate, monobromoacetate, monochloroacetate, dichloroacetate, and trichloroacetate on the exterior surface of $\mathrm{CB}[6]$ are observed in the negative mode electrospray ionization mass spectra. The strong binding energy of the complex allows intramolecular $\mathrm{S}_{\mathrm{N}} 2$ reaction of haloacetate, which yields externally bound $\mathrm{CB}[6]$-halide complex, by collisional activation. Utilizing ion mobility technique, structures of exteriorly bound $\mathrm{CB}[6]$ complexes of haloacetate and halide anions are confirmed. Theoretically determined low energy structures using density functional theory (DFT) further support results from ion mobility studies. The DFT calculation reveals that the binding energy and conformation of haloacetate on the $\mathrm{CB}[6]$ surface affect the efficiency of the intramolecular $\mathrm{S}_{\mathrm{N}} 2$ reaction of haloacetate, which correlate well with the experimental observation.
\end{abstract}

Key words: $\mathrm{CB}[6]$, Cucurbit[6]uril, Haloacetate, Halide, Anionic complex, Intramolecular $\mathrm{S}_{\mathrm{N}} 2$ reaction, Electrospray ionization, Ion mobility spectrometry

\section{Introduction}

Cucurbit $[n]$ urils $(\mathrm{CB}[n], n=5-8,10)$ are methylene$\checkmark$ bridged neutral macrocyclic molecules comprising $n$ glycoluril $\left[=\mathrm{C}_{4} \mathrm{H}_{2} \mathrm{~N}_{4} \mathrm{O}_{2}=\right]$ repeat units. $\mathrm{CB}[n]$ are effective host molecules in molecular recognition [1-4]. The unique host characteristics of $\mathrm{CB}[n]$ molecules have been widely applied in various fields for applications such as chiral recognition [5], metal interactions [4, 6], construction of

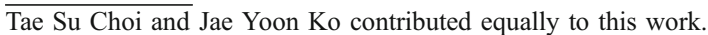

Electronic supplementary material The online version of this article (doi:10.1007/s13361-012-0443-6) contains supplementary material, which is available to authorized users.

Correspondence to: Hugh Kim; e-mail: hughkim@postech.edu supramolecular species [7, 8], drug/gene delivery [9-11], and recognition of peptides/proteins [12-16]. The unique host property of $\mathrm{CB}[n]$ results from two general features, their hydrophobic cavity and partial negatively-charged two carbonyl-laced portals, which respectively provide a potential site for the inclusion of a nonpolar residue and a binding site for positively charged functional groups of a guest molecule [1-4]. Another noticeable and characteristic feature in these neutral macrocyclic molecules is that the outer surface, especially the "equatorial" region, is highly positive, because the regions around carbonyl-laced portals of $\mathrm{CB}[n]$ are highly negative, as shown in the electrostatic surface potentials of CB[6] (Figure 1) [1,2]. Thus it is expected that noncovalent interactions may occur on the exterior surface with negatively charged molecules that may be as strong as

Received: 1 June 2012

Revised: 29 June 2012

Accepted: 29 June 2012

Published online: 4 August 2012 


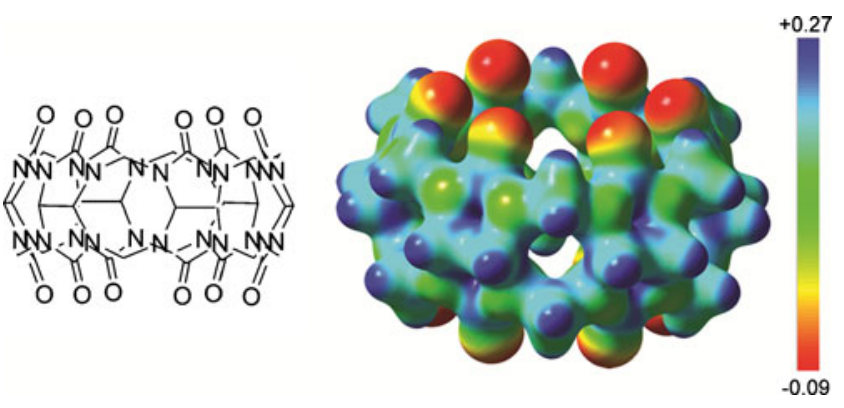

Figure 1. Structure of $\mathrm{CB}[6]$ (left) and electrostatic potential maps for $\mathrm{CB}[6]$ (right)

the host-guest interactions with positively charged molecules. There have been a few reports on the complexation of $\mathrm{CB}[n]$ with anions and anionic clusters, however, which occurs inside the cavity of $\mathrm{CB}[n][17,18]$. Yet, to the best of our knowledge, chemistry that occurs on the surface of the $\mathrm{CB}[n]$ has not been investigated. In the present study, for the first time, we report on the noncovalent interaction of $\mathrm{CB}[6]$ with anionic molecules on its exterior, and their chemical reactions in the gas phase using electrospray ionization mass spectrometry (ESI-MS). ESI-MS is a proven technology to study the intrinsic chemistry of supramolecular complexes in the absence of solvent effects [19], including host-guest chemistry of $\mathrm{CB}[n]$ supramolecular complexes [20-25]. Especially, interfacing ion mobility spectrometry with ESIMS has become a powerful tool for screening the structures of supramolecular complexes [26-30]. Of particular interest is the strong binding of haloacetate anions on the exterior of $\mathrm{CB}[6]$ without host-guest interaction. This strong binding allows complex phase reactions of haloacetate anions on the $\mathrm{CB}[6]$ exterior surface. The complex formation of $\mathrm{CB}[6]$ with a series of haloacetate anions with a different halide group is investigated using monoiodoacetate (MIA), monobromoacetate (MBA), and monochloroacetate (MCA). Chloroacetate anions with a different number of chloride, dichloroacetate (DCA) and trichloroacetate (TCA) are also investigated (see Scheme 1 for the structures of haloacetate ions).

\section{Experimental}

\section{Chemicals and Reagents}

All haloacetic acids except for dichloroacetic acid were purchased from Sigma-Aldrich (St. Louis, MO, USA). Dichloroacetic acid was purchased from Tokyo Chemical Industry (Tokyo, Japan). All solvents (water and acetonitrile) are HPLC grade and purchased from J. T. Baker

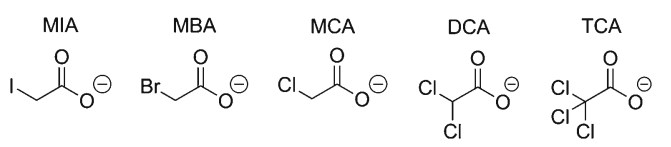

Scheme 1. Haloacetate anions investigated in the present study
(Phillipsburg, NJ, USA). $\mathrm{CB}[6]$ is synthesized by the reaction of glycoluril and formaldehyde based on a literature procedure [2]. $\mathrm{CB}[6]$ stock solution $(1 \mathrm{mg} / \mathrm{mL})$ is prepared by dissolving $\mathrm{CB}[6]$ in $98 \%$ formic acid. The stock solution $(50 \mu \mathrm{L})$ is added to $950 \mu \mathrm{L}$ solvent consisting $50 / 50$ water and acetonitrile by volume. ESI-MS spectrum of the diluted $\mathrm{CB}[6]$ solution is tested before haloacetic acid is added. Singly negative charged $\mathrm{CB}[6]$-formate complex is observed as the predominant peak in the ESI-MS spectrum (Figure S1). Seven different amounts of haloacetic acid are added to determine the appropriate concentration of haloacetic acid to generate predominant $\mathrm{CB}[6]$-haloacetate complex ion without interference from the complex formation of $\mathrm{CB}[6]$ with formate in the ESI-MS spectrum. As seen in Figure S1, the $\mathrm{CB}[6]$-haloacetate complex ions dominate ESI-MS spectra when haloacetate concentration is $10^{-2}$ times smaller than formate in the solution (Figure S2). The $1 \mu \mathrm{L}$ of haloacetic acid (liquid), which is heated up to $107^{\circ} \mathrm{C}$, is finally added to the diluted solutions in the oven for electrospray ionization (ESI). The final concentration for the ESI-MS experiment (water/acetonitrile 1:1 with $1 \mathrm{M}$ formic acid) is adjusted as $50 \mu \mathrm{M} \mathrm{CB}[6]$ with less than $1 \%$ haloacetic acid, which corresponds to $\sim 10 \mathrm{mM}$. All haloacetic acid was carefully handled during performing experiments because of its high toxicity to DNA and metabolism inhibition [31, 32].

\section{Electrospray Ionization Ion Mobility Mass Spectrometer}

The experiments of $\mathrm{CB}[6]$ complexes of haloacetate anions are performed on a Waters Synapt G2 HDMS traveling wave ion mobility orthogonal acceleration time-of-flight (Waters, Manchester, the UK) in negative ion mode. Source temperature of $80{ }^{\circ} \mathrm{C}$, capillary voltage of $2.00 \mathrm{kV}$, desolvation temperature of $250{ }^{\circ} \mathrm{C}$, and cone voltage of $40 \mathrm{~V}$ are set as parameters for ESI. Helium gas is introduced to the helium cell at a flow rate of $150 \mathrm{~mL} / \mathrm{min}$. Nitrogen drift gas is introduced to the traveling wave ion mobility spectrometry (TWIMS) stacked ring ion guide (SRIG) at a $30 \mathrm{~mL} / \mathrm{min}$ flow rate. The optimized traveling wave (T-wave) height and velocity are $13 \mathrm{~V}$ and $300 \mathrm{~m} / \mathrm{s}$, respectively. For each sample, 116 spectra are obtained and averaged for analysis. The drift times of analyte ions are determined from the location of the ion mobility peak maxima extracted using MassLynx (ver. 4.1) software (Waters, Milford, MA, USA).

\section{Collision Cross Section}

The experimental collision cross sections $\left(\Omega_{\mathrm{D}}\right)$ of $\mathrm{CB}[6]-$ haloacetate and $\mathrm{CB}[6]$-halide are evaluated using calibration method [33]. Polyalanine is used to create a calibration curve with previously published $\Omega_{\mathrm{D}}$ values [34]. The effective drift time of the calibrant is corrected for mass independent and mass dependent time. The effective drift time is plotted against the corrected published collision cross section. The plot is used to fit following previously described methods 
[33]. The equation from the fitting result is used to estimate $\Omega_{\mathrm{D}}$ of observed CB[6] complex ions. Theoretical $\Omega_{\mathrm{D}}$ of the $\mathrm{CB}[6]-\mathrm{MCA}$ and $\mathrm{CB}[6]-\mathrm{Cl}$ complexes are calculated by project approximation (PA) method, which is based on hard sphere description of the interaction potential [35]. The coordination of sample ions is obtained from the computational modeling described below.

\section{Computational Modeling}

Structures of CB[6]-haloacetate complexes in the gas phase are investigated to explain the mechanisms and dynamics of the observed reactions. Structures and energetics of CB[6] complexes of HA and halides in gas phase are determined by density functional theory (DFT) calculations using a Gaussian 09 (Gaussian Inc., Wallingford, CT, USA) utilizing the Becke three-parameter functional (B3) combined with the correlation functional of Lee, Yang, and Parr (LYP) [36-38]. More than 50 possible molecular conformations are investigated as initial complex structures. Six geometries with different locations of an anion in $\mathrm{CB}[6]$ are set as candidates using the 6-31 G basis set [39]. Further DFT optimizations are carried out using $6-31+\mathrm{G}(\mathrm{d})$ basis set without basis set superposition error and zero point energy correction [40, 41]. Transition state and intermediate products for intramolecular $\mathrm{S}_{\mathrm{N}} 2$ reaction of MCA are evaluated through scanning the length between chloride and $\alpha$-carbon from $1.8 \AA$ to $4.0 \AA$ with $0.1 \AA$ scanning step.

\section{Results and Discussion}

\section{ESI-MS ${ }^{n}$ Study of CB[6]-Haloacetate Complexes}

The ESI-MS spectra of $\mathrm{CB}[6]$ and haloacetate mixtures show singly charged $\mathrm{CB}[6]$-haloacetate complex anions as

(a)

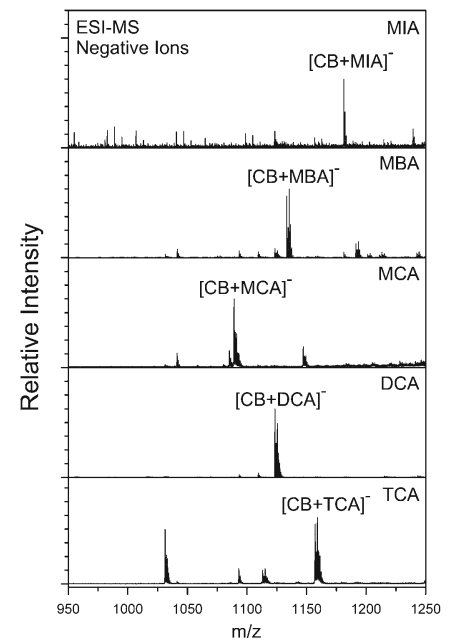

the most prominent peaks (Figure 2a). CB[6] complex anions of MIA, MBA, and MCA are found at $\mathrm{m} / \mathrm{z} 1181$, 1133, and 1089, respectively. CB[6]-DCA and CB[6]-TCA complex anions are found at $\mathrm{m} / z 1123$ and 1157 , respectively. This is somewhat unusual as $\mathrm{CB}[6]$ is known to form complexes readily with positively charged molecules such as aliphatic or aromatic ammonium cations [2]. Each CB[6] complex of haloacetate is isolated in the quadrupole followed by assigning collision energy in the ion trap. The collisional activation of $\mathrm{CB}[6]$-haloacetate yields a $\mathrm{CB}[6]-$ halide complex as a major fragment product except for MCA and DCA (Figure 2b) [42]. Haloacetate anions that result from a dissociation of the noncovalent bond with $\mathrm{CB}[6]$ are also observed. $\mathrm{CB}[6]$ complex of MIA and MBA also shows $\mathrm{I}^{-}$and $\mathrm{Br}^{-}$ions, respectively, without $\mathrm{CB}[6]$ as a major product. Notably, free haloacetate anions resulting from simple dissociation from $\mathrm{CB}[6]$ complexes are observed as the dominating product from collision induced dissociation (CID) of MCA and DCA.

\section{Ion Mobility Study of CB[6]-Haloacetate and $C B[6]$-Halide Complexes}

Previously, it has been confirmed from ion mobility studies that supramolecular complexes of $\mathrm{CB}[6]$ and molecules with cationic functional groups are formed via host-guest interactions $[23,29]$. However, it is unlikely that anionic haloacetates are interacting with $\mathrm{CB}[6]$ via host-guest interactions. Ion mobilities and related collision cross sections $\left(\Omega_{\mathrm{D}}\right)$ of $\mathrm{CB}[6]$-haloacetate reactants and $\mathrm{CB}[6]-$ halide products are measured using ion mobility mass spectrometry (IM-MS). Overall, the $\Omega_{\mathrm{D}}$ of anionic $\mathrm{CB}[6]$ complexes correlate well with the sizes of haloacetates and halides (Figure 3). CB[6]-MIA complex shows the largest

(b)

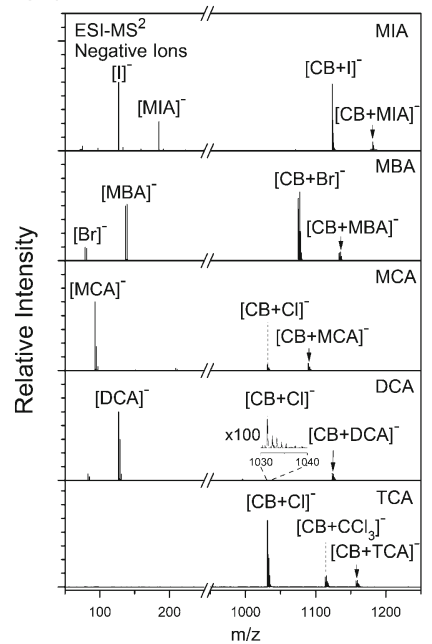

Figure 2. (a) A series of ESI-MS spectrum of mixture of $C B[6]$ and MIA, MBA, MCA, DCA, and TCA in negative ion mode. Singly charged CB[6] complex anions of MIA, MBA, MCA, DCA, and TCA are found at $m / z 1181,1133,1089,1123$, and 1157 , respectively. (b) The low energy CID $\left(\mathrm{MS}^{2}\right)$ spectra of singly charged CB[6] complexes of MIA, MBA, MCA, DCA, and TCA in negative ion mode. The parent ion is indicated with an arrow. Singly charged $\mathrm{CB}[6]$ complex anions of $\mathrm{I}^{-}, \mathrm{Br}^{-}$and $\mathrm{Cl}^{-}$are found at $m / z 1123,1075$, and 1031, respectively 
(a)

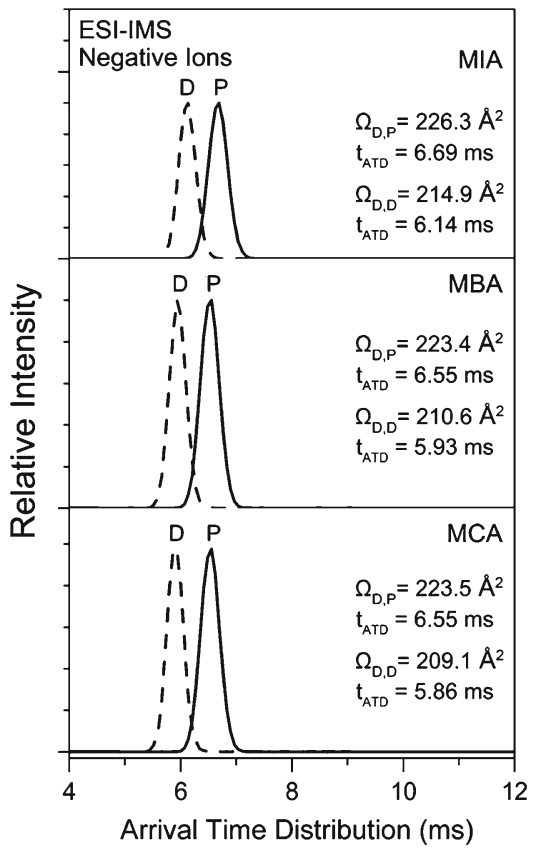

(b)

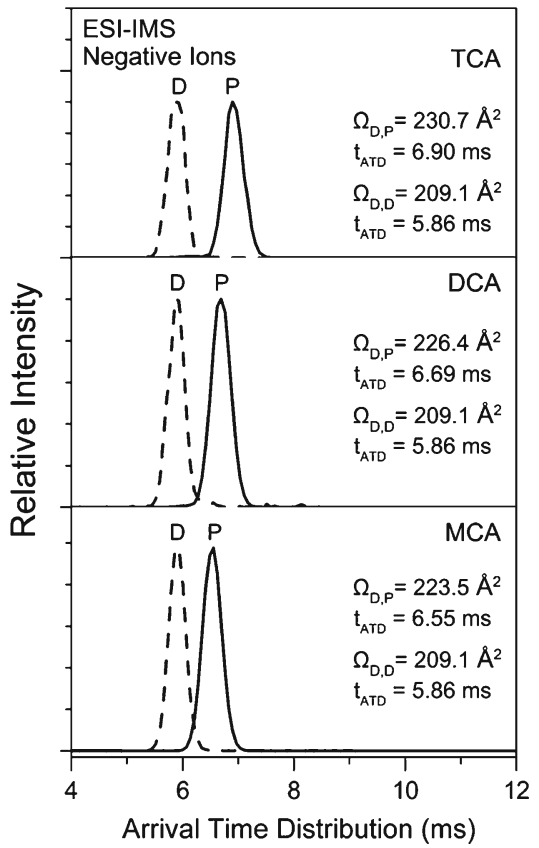

Figure 3. (a) lon mobility spectra of precursor ions, $C B[6]$ complexes of MIA, MBA, and MCA, are shown in solid line and CID product ions, which correspond to $\mathrm{CB}[6]$ of $\mathrm{I}^{-}, \mathrm{Br}^{-}$, and $\mathrm{Cl}^{-}$, are shown in dotted line. (b) lon mobility spectra of precursor ions, $\mathrm{CB}[6]$ complexes of TCA, DCA, and MCA, are shown in solid line and CID product ions, which correspond to $\mathrm{CB}[6]$ of $\mathrm{Cl}^{-}$, are shown in dotted line. Note that precursor and product ions are synonymous with parent ions $(P)$ and daughter ions $(D)$, respectively

$\Omega_{\mathrm{D}}$ among $\mathrm{CB}[6]$ complexes of monohaloacetate. It is of note that $\Omega_{\mathrm{D}}$ of $\mathrm{CB}[6]-\mathrm{MBA}$ and $\mathrm{CB}[6]-\mathrm{MCA}$ are comparable while relatively significant increase of $\Omega_{\mathrm{D}}$ is observed with $\mathrm{CB}[6]-\mathrm{MIA}$. In the $\mathrm{CB}[6]$-haloacetate complex, rigid $\mathrm{CB}[6]$ occupies $\sim 90 \%$ of $\Omega_{\mathrm{D}}$ of the complex [29]. The observed overall difference of $\Omega_{\mathrm{D}}$ of complex is caused by relatively small differences of binding geometries and sizes of small haloacetate anions [43]. A relatively small difference between MBA and MCA is difficult to be fully resolved using ion mobility separation technique in the present study. However, the correlation between mass and mobility is more clearly observed with $\mathrm{CB}[6]$-multichloroacetate complex anions. For $\mathrm{CB}[6]-$ multichloroacetate complexes, $\Omega_{\mathrm{D}}$ increases as the number of chlorine increases. This indicates that a haloacetate anion is bound to the exterior surface of $\mathrm{CB}[6]$ and this noncovalent binding is not via host-guest chemistry. This is further supported by the CID products of $\mathrm{CB}[6]$-halide complexes. As the size of halide anion decreases from iodide to chloride, the $\Omega_{\mathrm{D}}$ of $\mathrm{CB}[6]$ complex of halide anion decreases. If the interaction between $\mathrm{CB}[6]$ and haloacetate anion occurs inside of the cavity, no significant change of the complex $\Omega_{\mathrm{D}}$ would be observed. One example is found from our previous study [29], which shows that the $\Omega_{\mathrm{D}}$ of doubly protonated $\mathrm{CB}[6]$ and the $\mathrm{CB}[6]$ complex of 5-iminopentylammonium $\left({ }^{+} \mathrm{NH}_{2} \mathrm{CH}\left(\mathrm{CH}_{2}\right)_{4} \mathrm{NH}_{3}{ }^{+}\right)$are identical, as 5-iminopentylammonium threads through the $\mathrm{CB}[6]$ via host-guest interaction. The experimentally determined $\Omega_{\mathrm{D}}$ values of $\mathrm{CB}[6]$-haloacetate and $\mathrm{CB}[6]$-halide complex ions are summarized in Table 1.

Theoretically calculated $\Omega_{\mathrm{D}}$ values further support that haloacetate and halide anions are bound to the outer surface of $\mathrm{CB}[6]$. The experimentally determined $\Omega_{\mathrm{D}}$ values of singly charged $\mathrm{CB}[6]-\mathrm{MCA}$ and $\mathrm{CB}[6]-\mathrm{Cl}$ complex anions are $223.5 \AA^{2}$ and $209.1 \AA^{2}$, respectively (Figure 4). Compared with the experimental $\Omega_{\mathrm{D}}$, the theoretical $\Omega_{\mathrm{D}}$ agrees well with externally bound anions. Theoretical $\Omega_{\mathrm{D}}$ of the $\mathrm{CB}[6]-\mathrm{MCA}$ complex structure, where MCA bound to the external surface of $\mathrm{CB}[6]$, is calculated to be $219.4 \AA^{2}$. Theoretical $\Omega_{\mathrm{D}}$ of externally bound $\mathrm{CB}[6]-\mathrm{Cl}$ complex $\left(201.8 \AA^{2}\right)$ also shows good agreement with experimentally determined $\Omega_{\mathrm{D}}$. The complex structures whose MCA and $\mathrm{Cl}$ are located inside of the $\mathrm{CB}[6]$ cavity show almost identical

Table 1. Experimentally determined collision cross sections of CB[6]-haloacetate and $\mathrm{CB}[6]$-halide complex ions investigated in the present study. Collision cross section of $\mathrm{CB}[6]$ complex of ${ }^{[a]}$ Haloacetate anion (HA) and ${ }^{[b]}$ Halide anion (X)

\begin{tabular}{llllrr}
\hline & MIA & MBA & MCA & DCA & TCA \\
\hline$\Omega_{\mathrm{D}, \mathrm{HA}}^{[\mathrm{a}]}\left(\AA^{2}\right)$ & $226.3 \pm 4.8$ & $223.4 \pm 4.6$ & $223.5 \pm 4.6$ & $226.4 \pm 4.1$ & $230.7 \pm 4.8$ \\
$\Omega_{\mathrm{D}, \mathrm{X}}{ }^{2}\left(\AA^{2}\right)$ & $214.9 \pm 4.6$ & $210.6 \pm 3.9$ & $209.1 \pm 4.6$ & $209.1 \pm 4.0$ & $209.1 \pm 4.0$ \\
\hline
\end{tabular}


(a)

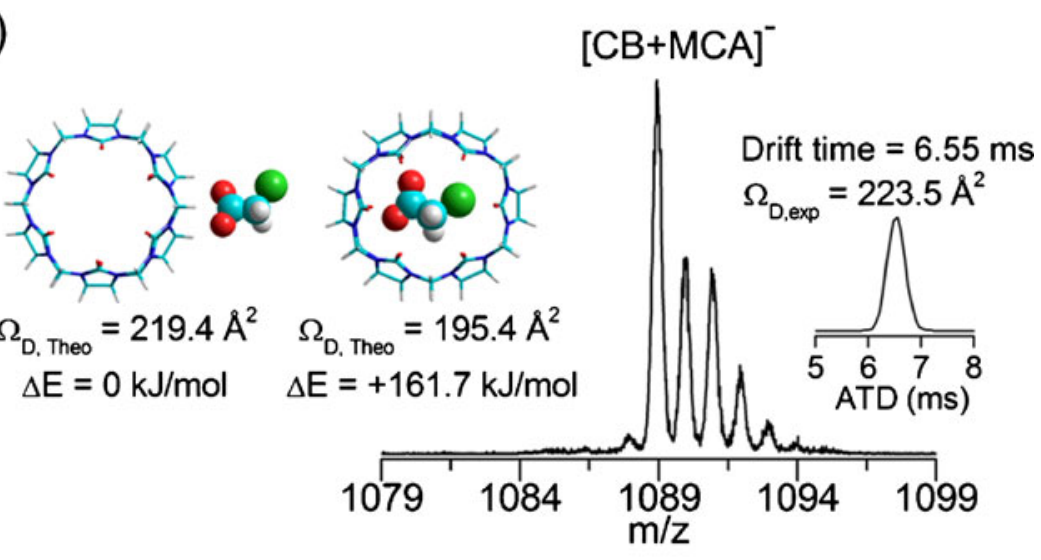

(b)
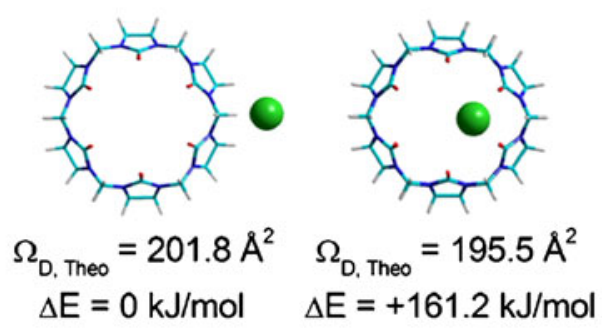

$[\mathrm{CB}+\mathrm{Cl}]^{-}$

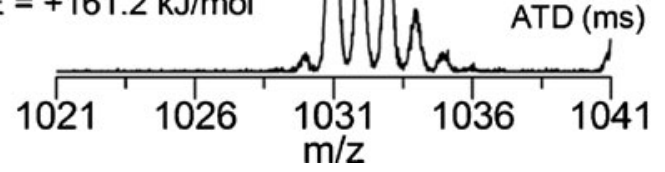

Figure 4. ESI-MS spectra of singly charged (a) CB[6]-MCA complex anion and (b) $\mathrm{CB}[6]-\mathrm{Cl}$ complex anion. Arrival time distribution and experimental $\Omega_{D}$ of the designated peak is shown as the right inset. DFT optimized structures of singly charged complex anions and their theoretical $\Omega_{D}$ are shown as the left inset

theoretical $\Omega_{\mathrm{D}}\left(195.4 \AA^{2}\right.$ and $195.5 \AA^{2}$, respectively). The DFT calculation also indicates that the externally bound structures of $\mathrm{CB}[6]-\mathrm{MCA}$ and $\mathrm{CB}[6]-\mathrm{Cl}$ complexes are lower in energy by $\sim 161 \mathrm{~kJ} \mathrm{~mol}^{-1}$ compared to the internally bound structure. Both haloacetate reactant and halide product are observed on the surface of $\mathrm{CB}[6]$ indicating the reaction occurs on the surface of $\mathrm{CB}[6]$.

\section{Intramolecular $S_{N} 2$ Reaction of Haloacetate on the Surface of $C B[6]$}

The process to yield halide anion from haloacetate is known to involve the internal $\mathrm{S}_{\mathrm{N}} 2$ reaction, which results from nucleophilic attack of carboxylate oxygen to $\alpha$-carbon with halide leaving group (Scheme 2) [42, 44, 45]. Both haloacetate reactant and halide product are observed on the surface of $\mathrm{CB}[6]$ indicating the reaction occurs on the surface of $\mathrm{CB}[6]$. The reaction-efficiency curve in Figure 5a

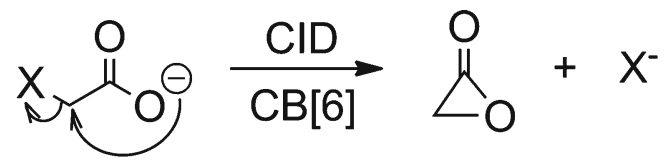

Scheme 2. Intramolecular $\mathrm{S}_{\mathrm{N}} 2$ reaction of haloacetate anion for $\mathrm{CB}[6]$ complex of each monohaloacetate shows that the reaction efficiency follows the leaving group ability of halide ion $\left(\mathrm{I}^{-}>\mathrm{Br}^{-}>\mathrm{Cl}^{-}\right)$[46]. It is notable that a dramatic decrease of product fraction occurs with MCA is compared with product fractions of MIA and MBA. A criterion for the chemical reaction in a noncovalently bound complex is that the binding energy of a complex must be stronger than the activation barrier for a reaction [47]. Otherwise, simple dissociation of noncovalent bond occurs by collisional activation. This infers that the activation barriers for the intramolecular $\mathrm{S}_{\mathrm{N}} 2$ reaction of haloacetate anions are, in general, lower than the binding energy of the complexes with $\mathrm{CB}[6]$. For the multichloroacetate anions (Figure 5b), as the number of chlorine at $\alpha$-carbon increases, charge deficiency to $\alpha$-carbon increases. Furthermore, this induces the preference for nucleophilic attack of carboxylate oxygen to $\alpha$-carbon. Then, it is expected that there would be a gradual increase of the reaction efficiency as the number of chlorine increases. TCA shows that the highest efficiency for the reaction, but the reaction efficiency for DCA is lower than MCA. The DFT calculation indicates two factors affect the $\mathrm{S}_{\mathrm{N}} 2$ reaction of multichloroacetate on the surface of $\mathrm{CB}[6]$ (Figure 6). First, the binding energy between $\mathrm{CB}[6]$ and the haloacetate anion should be strong enough as 
(a)

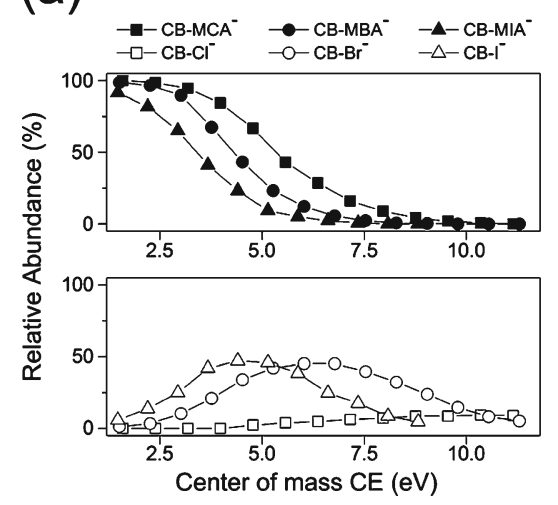

(b)

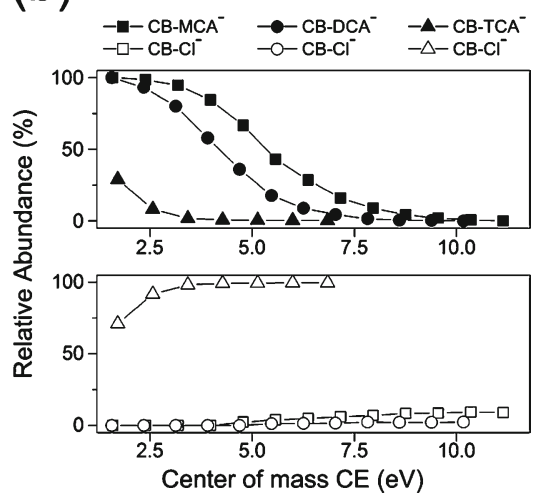

Figure 5. Plots of fraction of $\mathrm{CB}[6]$ complexes of (a) MIA, MBA, and MCA and (b) TCA, DCA, and MCA as a function of center of mass collision energy (top). Plots of fraction of $\mathrm{CB}[6]$ complexes of (a) $\mathrm{I}^{-}, \mathrm{Br}^{-}$, and $\mathrm{Cl}^{-}$from MIA, MBA, and MCA and (b) $\mathrm{Cl}^{-}$ ions from TCA, DCA, and MCA as a function of center of mass collision energy (bottom)

discussed earlier. The DFT calculations show that the binding energies of $\mathrm{CB}[6]$ complexes of MCA, DCA, and TCA are $153.0 \mathrm{~kJ} \mathrm{~mol}^{-1}, 144.6 \mathrm{~kJ} \mathrm{~mol}^{-1}$, and $136.6 \mathrm{~kJ} \mathrm{~mol}^{-}$ ${ }^{1}$, respectively. This indicates that the barrier height of intramolecular $\mathrm{S}_{\mathrm{N}} 2$ reaction for MCA is around or slightly higher than $153.0 \mathrm{~kJ} \mathrm{~mol}^{-1}$, while it is lower than $136.6 \mathrm{~kJ} \mathrm{~mol}^{-1}$ for TCA. The DFT calculated energetics for the intramolecular $\mathrm{S}_{\mathrm{N}} 2$ reaction of MCA show a good agreement with this interpretation (Figure S3). The overall barrier for the intramolecular $\mathrm{S}_{\mathrm{N}} 2$ reaction of MCA in the $\mathrm{CB}[6]-\mathrm{MCA}$ complex is calculated as $170 \mathrm{~kJ} \mathrm{~mol}^{-1}$. Second, the conformation of the haloacetate anion affects the reaction efficiency. The observed lower reaction efficiency of DCA over MCA is attributed to the symmetric gauche conformation between nucleophilic carboxylate oxygen and chlorine leaving groups of DCA (Scheme 3).

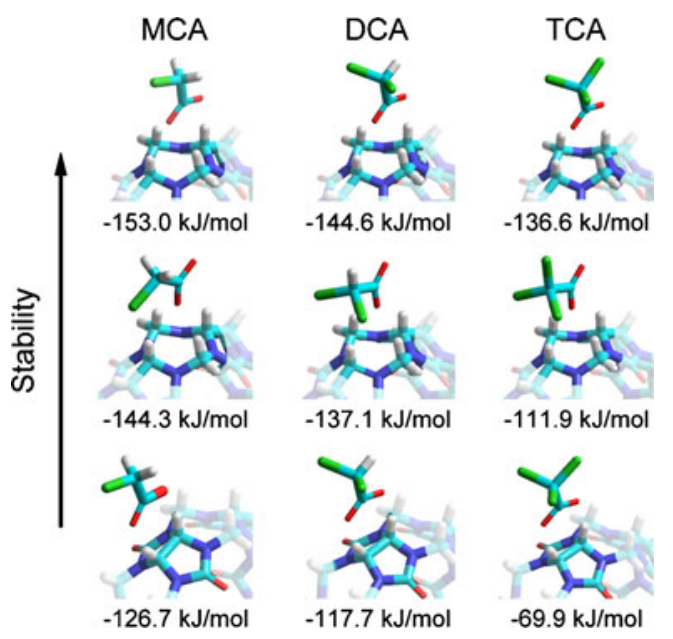

Figure 6. Optimized structures of the mono-, di-, trichloroacetate anions on the surface of $\mathrm{CB}[6]$ using DFT at the B3LYP/6-31+G(d) level. The binding energy of the structure is shown below

\section{The Role of $C B[6]$ Surface in the Intramolecular $S_{N} 2$ Reaction of Haloacetate}

In order to understand the role of $\mathrm{CB}[6]$ in the observed $\mathrm{S}_{\mathrm{N}} 2$ reactions of haloacetate anions in the complex, we examine the reaction of MBA and MIA anions without $\mathrm{CB}[6]$ in the gas phase (Figure S4). MCA is not examined due to the low mass range limit $(\mathrm{m} / \mathrm{z} 50)$ of the instrument to detect chloride anion whose $m / z$ is 35 . Both MBA and MIA show $\mathrm{Br}^{-}$and $\mathrm{I}^{-}$ as major product, respectively, by collisional activation. However, minor products of bromomethanide and iodomethanide, which result from decarboxylation, are also observed. Decarboxylation is the most common fragmentation pathway of a gas phase organic acid molecule [48, 49]. Haloacetate anions investigated in the present study either show an intramolecular $\mathrm{S}_{\mathrm{N}} 2$ reaction or dissociation of noncovalent bonding in the $\mathrm{CB}[6]$ complexes. This indicates that once the binding energy in the complex is strong enough, only an intramolecular $\mathrm{S}_{\mathrm{N}} 2$ reaction yields halide anion and acetolacton in the complex. As seen in Figure 6, haloacetate anion binds strongly to the surface of $\mathrm{CB}[6]$. In the $\mathrm{CB}[6]$-haloacetate complex, the oxygen atoms interact with methylene groups, which possess localized positive partial charges (Figure 1). Then, these methylene groups may provide surface for halide, stabilizing the transition state of the intramolecular $\mathrm{S}_{\mathrm{N}} 2$ reaction.

Iodine and bromine, which have high diffusivity, have higher preference to interact with the methylene group of $\mathrm{CB}[6]$. This may result in lowering the activation barrier for MBA and MIA showing facile intramolecular $\mathrm{S}_{\mathrm{N}} 2$ reactions.

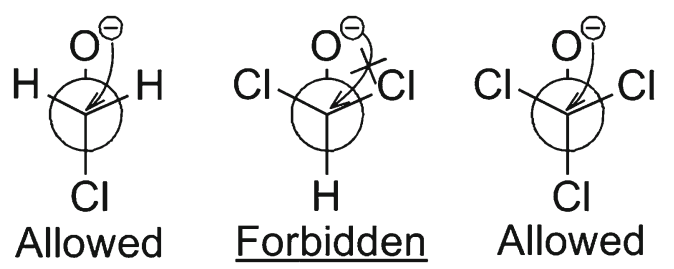

Scheme 3. Newmann projection of MCA, DCA, and TCA 
However, relatively rigid chlorine hardly interacts with the methylene group, which results in a difficult intramolecular $\mathrm{S}_{\mathrm{N}} 2$ reaction. In brief, the formation of the energetically favoured $\mathrm{CB}[6]$-haloacetate complex may lower the overall activation barrier of the reaction and further stabilize the intermediate for the observed $\mathrm{S}_{\mathrm{N}} 2$ reaction. As a result, $\mathrm{CB}[6]$ is considered to act as a catalyst to modify the energetics of intramolecular $\mathrm{S}_{\mathrm{N}} 2$ reactions of haloacetate anions in the complex.

\section{Conclusion}

A noncovalently bound $\mathrm{CB}[6]$ complex is formed between haloacetate anion and $\mathrm{CB}[6]$ in the gas phase via interaction between the carboxylate group of the haloacetate anion and highly-positive methylene groups of the $\mathrm{CB}[6]$ exterior. Strong binding energy between haloacetate anion and $\mathrm{CB}[6]$ allows facile intramolecular $\mathrm{S}_{\mathrm{N}} 2$ reaction of haloacetate, which yields externally bound $\mathrm{CB}[6]$-halide complex by collisional activation. Utilizing IM-MS technique exteriorly interacting $\mathrm{CB}[6]$-anion complex structures are confirmed. The observed strong interaction is expected to be used for a wide range of potential applications, specifically, for the design and formation of self-organized supramolecular structures. In addition, the rigid and highly partial positive exterior structure of $\mathrm{CB}[6]$ is also expected to be used for molecular catalysts as observed from the present study.

\section{Acknowledgments}

The authors acknowledge support for this work by Basic Science Research (to H.I.K.; grant no. 2010-0021508), the Acceleration Research, BK21, and WCU (KK; project no. R31-2008-000-10059-0) programs through the National Research Foundation (NRF) of Korea funded by the Ministry of Education, Science, and Technology (MOEST). This work was also supported by the POSTECH Basic Science Research Institute grant (to H.I.K.).

\section{References}

1. Jeon, W.S., Moon, K., Park, S.H., Chun, H., Ko, Y.H., Lee, J.Y., Lee, E.S., Samal, S., Selvapalam, N., Rekharsky, M.V., Sindelar, V., Sobransingh, D., Inoue, Y., Kaifer, A.E., Kim, K.: Complexation of Ferrocene Derivatives by the Cucurbit[7]uril Host: A Comparative Study of the Cucurbituril and Cyclodextrin Host Families. J. Am. Chem. Soc. 127, 12984-12989 (2005)

2. Lee, J.W., Samal, S., Selvapalam, N., Kim, H.J., Kim, K.: Cucurbituril Homologues and Derivatives: New Opportunities in Supramolecular Chemistry. Acc. Chem. Res. 36, 621-630 (2003)

3. Kim, K., Selvapalam, N., Ko, Y.H., Park, K.M., Kim, D., Kim, J.: Functionalized Cucurbiturils and Their Applications. Chem. Soc. Rev. 36, 267-279 (2007)

4. Lagona, J., Mukhopadhyay, P., Chakrabarti, S., Isaacs, L.: The Cucurbit[n]uril Family. Angew. Chem. Int. Ed. 44, 4844-4870 (2005)

5. Rekharsky, M.V., Yamamura, H., Inoue, C., Kawai, M., Osaka, I., Arakawa, R., Shiba, K., Sato, A., Ko, Y.H., Selvapalam, N., Kim, K., Inoue, Y.: Chiral Recognition in Cucurbituril Cavities. J. Am. Chem. Soc. 128, 14871-14880 (2006)
6. Whang, D., Heo, J., Park, J.H., Kim, K.: A Molecular Bowl with Metal Ion as Bottom: Reversible Inclusion of Organic Molecules in Cesium Ion Complexed Cucurbituril. Angew. Chem. Int. Ed.. 37, 78-80 (1998)

7. Ko, Y.H., Kim, E., Hwang, I., Kim, K.: Supramolecular Assemblies Built with Host-Stabilized Charge-Transfer Interactions. Chem. Commun. 1305-1315 (2007)

8. Kim, K.: Mechanically Interlocked Molecules Incorporating Cucurbituril and Their Supramolecular Assemblies. Chem. Soc. Rev. 31, 96-107 (2002)

9. Lim, Y.B., Kim, T., Lee, J.W., Kim, S.M., Kim, H.J., Kim, K., Park, J.S.: Self-Assembled Ternary Complex of Cationic Dendrimer, Cucurbituril, and DNA: Noncovalent Strategy in Developing a Gene Delivery Carrier. Bioconjugate Chem. 13, 1181-1185 (2002)

10. Kim, S.K., Park, K.M., Singha, K., Kim, J., Ahn, Y., Kim, K., Kim, W.J.: Galactosylated Cucurbituril-Inclusion Polyplex for HepatocyteTargeted Gene Delivery. Chem. Commun. 46, 692-694 (2010)

11. Park, K.M., Lee, D.-W., Sarkar, B., Jung, H., Kim, J., Ko, Y.H., Lee, K.E., Jeon, H., Kim, K.: Reduction-Sensitive, Robust Vesicles with a Noncovalently Modifiable Surface as a Multifunctional Drug-Delivery Platform. Small 6, 1430-1441 (2010)

12. Bush, M.E., Bouley, N.D., Urbach, A.R.: Charge-Mediated Recognition of N-Terminal Tryptophan in Aqueous Solution by a Synthetic Host. J. Am. Chem. Soc. 127, 14511-14517 (2005)

13. Reczek, J.J., Kennedy, A.A., Halbert, B.T., Urbach, A.R.: Multivalent Recognition of Peptides by Modular Self-Assembled Receptors. J. Am. Chem. Soc. 131, 2408-2415 (2009)

14. Urbach, A.R., Ramalingam, V.: Molecular Recognition of Amino Acids, Peptides, and Proteins by Cucurbit[n]uril Receptors. Israel J. Chem. 51, 664-678 (2011)

15. Chinai, J.M., Taylor, A.B., Ryno, L.M., Hargreaves, N.D., Morris, C.A., Hart, P.J., Urbach, A.R.: Molecular Recognition of Insulin by a Synthetic Receptor. J. Am. Chem. Soc. 133, 8810-8813 (2011)

16. Lee, D.W., Park, K.M., Banerjee, M., Ha, S.H., Lee, T., Suh, K., Paul, S., Jung, H., Kim, J., Selvapalam, N., Ryu, S.H., Kim, K.: Supramolecular Fishing for Plasma Membrane Proteins Using an Ultrastable Synthetic Host-Guest Binding Pair. Nat. Chem. 3, 154-159 (2011)

17. Liu, J.X., Long, L.S., Huang, R.B., Zheng, L.S.: Molecular Capsules Based on Cucurbit[5] uril Encapsulating "Naked" Anion Chlorine. Cryst. Growth Des. 6, 2611-2614 (2006)

18. Liu, J.X., Long, L.S., Huang, R.B., Zheng, L.S.: Interesting AnionInclusion Behavior of Cucurbit[5]uril and Its Lanthanide-Capped Molecular Capsule. Inorg. Chem. 46, 10168-10173 (2007)

19. Schalley, C.A.: Supramolecular Chemistry Goes Gas Phase: The Mass Spectrometric Examination of Noncovalent Interactions in Host-Guest Chemistry and Molecular Recognition. Int. J. Mass Spectrom. 194, 1139 (2000)

20. Zhang, H., Ferrell, T.A., Asplund, M.C., Dearden, D.V.: Molecular Beads on a Charged Molecular String: $\alpha, \omega$-Alkyldiammonium Complexes of Cucurbit[6] uril in the Gas Phase. Int. J. Mass Spectrom. 265, 187-196 (2007)

21. Zhang, H., Paulsen, E.S., Walker, K.A., Krakowiak, K.E., Dearden, D.V.: Cucurbit[6]uril Pseudorotaxanes: Distinctive Gas-Phase Dissociation and Reactivity. J. Am. Chem. Soc. 125, 9284-9285 (2003)

22. Dearden, D.V., Ferrell, T.A., Asplund, M.C., Zilch, L.W., Julian, R.R., Jarrold, M.F.: One Ring to Bind Them All: Shape-Selective Complexation of Phenylenediamine Isomers with Cucurbit[6]uril in the Gas Phase. J. Phys. Chem. A 113, 989-997 (2009)

23. Zhang, H., Grabenauer, M., Bowers, M.T., Dearden, D.V.: Supramolecular Modification of Ion Chemistry: Modulation of Peptide Charge State and Dissociation Behavior through Complexation with Cucurbit[n]uril $(\mathrm{N}=5,6)$ or $\alpha$-Cyclodextrin. J. Phys. Chem. A 113, 15081517 (2009)

24. Deroo, S., Rauwald, U., Robinson, C.V., Scherman, O.A.: Discrete, Multi-Component Complexes with Cucurbit[8]uril in the Gas-Phase. Chem. Commun. 644-646 (2009)

25. Rauwald, U., Biedermann, F., Deroo, S., Robinson, C.V., Scherman, O.A.: Correlating Solution Binding and Esi-Ms Stabilities by Incorporating Solvation Effects in a Confined Cucurbit[8]uril System. J. Phys. Chem. B 114, 8606-8615 (2010)

26. Gidden, J., Ferzoco, A., Baker, E.S., Bowers, M.T.: Duplex Formation and the Onset of Helicity in Poly d(CG) Oligonucleotides in a SolventFree Environment. J. Am. Chem. Soc. 126, 15132-15140 (2004) 
27. Julian, R.R., Hodyss, R., Kinnear, B., Jarrold, M.F., Beauchamp, J.L.: Nanocrystalline Aggregation of Serine Detected by Electrospray Ionization Mass Spectrometry: Origin of the Stable Homochiral GasPhase Serine Octamer. J. Phys. Chem. B 106, 1219-1228 (2002)

28. Counterman, A.E., Clemmer, D.E.: Magic Number Clusters of Serine in the Gas Phase. J. Phys. Chem. B 105, 8092-8096 (2001)

29. Heo, S.W., Choi, T.S., Park, K.M., Ko, Y.H., Kim, S.B., Kim, K., Kim, H.I.: Host-Guest Chemistry in the Gas Phase: Selected Fragmentations of CB[6] -Peptide Complexes at Lysine Residues and Its Utility to Probe the Structures of Small Proteins. Anal. Chem. 83, 7916-7923 (2011)

30. Ko, J.Y., Heo, S.W., Lee, J.H., Oh, H.B., Kim, H., Kim, H.I.: HostGuest Chemistry in the Gas Phase: Complex Formation with 18-Crown6 Enhances Helicity of Alanine-Based Peptides. J. Phys. Chem. A 115, 14215-14220 (2011)

31. Nelson, G.M., Swank, A.E., Brooks, L.R., Bailey, K.C., George, S.E.: Metabolism, Microflora Effects, and Genotoxicity in Haloacetic AcidTreated Cultures of Rat Cecal Microbiota. Toxicol. Sci. 60, 232-241 (2001)

32. Pals, J.A., Ang, J.K., Wagner, E.D., Plewa, M.J.: Biological Mechanism for the Toxicity of Haloacetic Acid Drinking Water Disinfection Byproducts. Environ. Sci. Technol. 45, 5791-5797 (2011)

33. Thalassinos, K., Grabenauer, M., Slade, S.E., Hilton, G.R., Bowers, M.T., Scrivens, J.H.: Characterization of Phosphorylated Peptides Using Traveling Wave-Based and Drift Cell Ion Mobility Mass Spectrometry. Anal. Chem. 81, 248-254 (2009)

34. Valentine, S.J., Counterman, A.E., Clemmer, D.E.: A Database of 660 Peptide Ion Cross Sections: Use of Intrinsic Size Parameters for Bona Fide Predictions of Cross Sections. J. Am. Soc. Mass Spectrom. 10, 1188-1211 (1999)

35. Wyttenbach, T., von Helden, G., Batka, J., Carlat, D., Bowers, M.: Effect of the Long-Range Potential on Ion Mobility Measurements. $J$. Am. Soc. Mass Spectrom. 8, 275-282 (1997)

36. Becke, A.D.: Density-Functional Thermochemistry. 3. The Role of Exact Exchange. J. Chem. Phys. 98, 5648-5652 (1993)

37. Frisch, M.J., Trucks, G.W., Schlegel, H.B., Scuseria, G.E., Robb, M.A., Cheeseman, J.R., Scalmani, G., Barone, V., Mennucci, B., Petersson, G.A., Nakatsuji, H., Caricato, M., Li, X., Hratchian, H.P., Izmaylov, A.F., Bloino, J., Zheng, G., Sonnenberg, J.L., Hada, M., Ehara, M., Toyota, K., Fukuda, R., Hasegawa, J., Ishida, M., Nakajima, T., Honda, Y., Kitao, O., Nakai, H., Vreven, T., Montgomery, J., J. A., Peralta, J.E., Ogliaro, F., Bearpark, M., Heyd, J.J., Brothers, E., Kudin, K.N., Staroverov, V.N., Kobayashi, R., Normand, J., Raghavachari, K., Rendell, A., Burant, J.C., Iyengar, S.S., Tomasi, J., Cossi, M., Rega, N., Millam, N.J., Klene, M., Knox, J.E., Cross, J.B., Bakken, V., Adamo, C., Jaramillo, J., Gomperts, R., Stratmann, R.E., Yazyev, O.,
Austin, A.J., Cammi, R., Pomelli, C., Ochterski, J.W., Martin, R.L., Morokuma, K., Zakrzewski, V.G., Voth, G.A., Salvador, P., Dannenberg, J.J., Dapprich, S., Daniels, A.D., Farkas, Ö., Foresman, J.B., Ortiz, J.V., Cioslowski, J., Fox, D.J.: Gaussian 09, Rev. A.1. Gaussian, Inc.: Wallingford CT, (2009)

38. Lee, C.T., Yang, W.T., Parr, R.G.: Development of the Colle-Salvetti Correlation-Energy Formula into a Functional of the Electron-Density. Phys. Rev. B 37, 785-789 (1988)

39. Harihara.Pc, Pople, J.A.: Effect of d-Functions on Molecular Orbital Energies for Hydrocarbons. Chem. Phys. Lett. 16, 217 (1972)

40. Rassolov, V.A., Pople, J.A., Ratner, M.A., Windus, T.L.: 6-31g* Basis Set for Atoms K through Zn. J. Chem. Phys. 109, 1223-1229 (1998)

41. Rassolov, V.A., Ratner, M.A., Pople, J.A., Redfern, P.C., Curtiss, L.A. 6-31g* Basis Set for Third-Row Atoms. J. Comput. Chem. 22, 976-984 (2001)

42. Rodriquez, C.F., Williams, I.H.: Ab Initio Theoretical Investigation of the Mechanism for $\alpha$-Lactone Formation from $\alpha$-Halocarboxylates: Leaving Group, Substituent, Solvent, and Isotope Effects. J. Chem. Soc. Perkin Trans. 2, 959-965 (1997)

43. Kim, H., Kim, H.I., Johnson, P.V., Beegle, L.W., Beauchamp, J.L., Goddard, W.A., Kanik, I.: Experimental and Theoretical Investigation into the Correlation between Mass and Ion Mobility for Choline and Other Ammonium Cations in $\mathrm{N}_{2}$. Anal. Chem. 80, 1928-1936 (2008)

44. Antolovic, D., Shiner, V.J., Davidson, E.R.: Theoretical Study of $\alpha-$ Lactone, Acetoxyl Diradical, and the Gas-Phase Dissociation of the Chloracetate Anion. J. Am. Chem. Soc. 110, 1375-1381 (1988)

45. Graul, S.T., Squires, R.R.: Collisional Activation of Intramolecular Nucleophilic Displacement Reactions: The Formation of Acetolactone from Dissociation of $\alpha$-Haloacetate Negative Ions. Int. J. Mass Spectrom. Ion Processes 100, 785-802 (1990)

46. Huggins, M.L.: Bond Energies and Polarities1. J. Am. Chem. Soc. 75, 4123-4126 (1953)

47. Cox, H.A., Hodyss, R., Beauchamp, J.L.: Cluster-Phase Reactions: GasPhase Phosphorylation of Peptides and Model Compounds with Triphosphate Anions. J. Am. Chem. Soc. 127, 4084-4090 (2005)

48. Kim, H.I., Beauchamp, J.L.: Cluster Phase Chemistry: Collisions of Vibrationally Excited Cationic Dicarboxylic Acid Clusters with Water Molecules Initiate Dissociation of Cluster Components. J. Phys. Chem. A 111, 5954-5967 (2007)

49. Kim, H.I., Goddard, W.A., Beauchamp, J.L.: Cluster Phase Chemistry: Gas Phase Reactions of Anionic Sodium Salts of Dicarboxylic Acid Clusters with Water Molecules. J. Phys. Chem. A 110, 7777-7786 (2006) 